\title{
APLIKASI REKAM MEDIS DIGITAL PADA KLINIK MEDIKA KECAMATAN CONGGEANG
}

\author{
${ }^{1}$ Irfan Fadil, ${ }^{2}$ Fidi Supriadi \\ E-mail : ${ }^{1}$ fadilirfan@ stmik-sumedang.ac.id, ${ }^{2}$ fsupriadi@ stmik-sumedang.ac.id
}

\begin{abstract}
Abstraksi
Rekam medis adalah keterangan baik yang tertulis maupun terekam tentang identitas, anamnesa, penentuan fisik, laboratorium, diagnosa segala pelayanan dan tindakan medik yang diberikan kepada pasien dan pengobatan baik yang dirawat inap, rawat jalan maupun yang mendapatkan pelayanan gawat darurat. Pengembangan sistem rekam medis ditujukan untuk mendukung ketersedian data informasi bagi manajemen dan pelaksana layanan serta pengembangan jaringan informasi kesehatan. Sistem ini dibangun dengan teknologi komputer berbasis mobile. Sistem rekam medis ini dibangun dengan menggunakan bahasa pemrograman Java dengan didukung basisdata MySQL. Sistem yang sedang berjalan sekarang ini menemui berbagai kendala dan permasalahan, terutama pada Pendaftaran Pasien, penggunaan basisdata dan sistem yang diterapkan hanya sebagai mesin pencatat. Dalam perkembangannya diharapkan sistem ini dapat diterapkan dalam jaringan intranet dan saling terhubung dengan instasi medis lain.
\end{abstract}

Kata Kunci : Rekam Medis Digital,Rekam Medis Berbasis Android, Rekam Medis Digital Klinik Medika.

\begin{abstract}
Medical records are written and recorded information about the identity, history, physical determination, laboratory, diagnosis of all services and medical actions given to patients and treatment both inpatient, outpatient and those receiving emergency services. The development of a medical record system is intended to support the availability of information data for management and service providers and the development of health information networks. This system was built with mobile-based computer technology. This medical record system was built using the Java programming language supported by a MySQL database. The current system runs into various obstacles and problems, especially in Patient Registration, the use of databases and systems that are applied only as recording machines. In its development it is hoped that this system can be applied in intranet networks and interconnected with other medical institutions.
\end{abstract}

Keywords: Digital Medical Records, Android Based Medical Records, Digital Medika Medical Records. 


\section{Pendahuluan}

Perkembangan teknologi yang kian pesat membawa dampak negatif dan positif pada seluruh lapisan bidang kehidupan, termasuk di dalam bidang kesehatan. Sistem yang didukung oleh pengolahan data yang tepat terbukti mampu mempercepat kinerja yang pada akhirnya akan menghasilkan manfaat yang besar bagi masyarakat. Data yang selama ini diolah secara konvensional dengan masih menggunakan cara pencatatan data-data (data pasien, data dokter, data perawat dan data kamar) melalui media buku yang dapat menimbulkan resiko yang cukup besar terhadap kerusakan dan kehilangan. Data yang kurang lengkap juga akan menyebabkan informasi pelayanan kesehatan juga kurang, karena data tidak tersusun rapi dan susahnya pencarian data yang mengurangi keakuratan dari data tersebut. Hal inilah yang masih dialami oleh Klinik Medika di kecamatan Conggeang yang merupakan salah satu instansi kesehatan yang sering dikunjungi oleh masyarakat sekitar, menurut data yang di dapatkan dari puskesmas tersebut setiap hari pasien yang berkunjung mencapai 70 orang. Berikut rekapan jumlah kunjungan pasien selama bulan Januari 2019 s/d Mei 2019 :

Tabel 1 Rekapan jumlah kunjungan pasien

\begin{tabular}{|c|c|}
\hline Bulan & Jumlah kunjungan \\
\hline Januari & 2.021 \\
\hline Pebruari & 1.050 \\
\hline Maret & 1.642 \\
\hline April & 1.985 \\
\hline Mei & 1.240 \\
\hline
\end{tabular}

Hasil survei yang telah dilakukan diketahui bahwa pada Klinik Medika Kecamatan Conggeang semua sistemnya dijalankan secara manual, meski ada beberapa komputer namun penggunaannya masih belum efektif. Hal tersebut dapat dilihat adanya beberapa bagian sistem yang mengharuskan pasien untuk antri berkali-kali pada saat pembagian poli dan karena lamanya petugas memasukan data bagi pasien yang baru pertama kali berkunjung dan proses pencarian data bagi anggota atau pasien lama di buku-buku besar yang begitu banyak. Oleh sebab itu, perlu dirancang sebuah sistem rekam medis yang bisa dijadikan sebagai solusi untuk mengolah data secara efektif dan efisien, sehingga dapat meminimalisir kesalahan-kesalahan yang muncul. Dimana pada akhirnya akan meningkatkan kepuasan pelayanan terhadap masyarakat serta bisa meningkatkan perkembangan puskesmas tersebut.

\section{Tinjauan Pustaka}

\section{Software Engineering}

Perkembangan Rekayasa Perangkat Lunak diawali pada tahun 1940-an sampai sekarang. Tujuan utama pengembangannya adalah untuk mengembangkan teknologi yang dapat mengembangkan produktivitas para praktisi pengembang perangkat lunak atau disebut juga developer aplikasi dan juga meningkatkan kualitas hasil produksi para praktisi tersebut.

Menurut Heidi J. C. Ellis dan J. Fernando Naveda, (2009:2), "masalah kunci dari rekayasa perangkat lunak terdapat pada ukuran dan kompleksitas yang jelas diakui, seperti kesulitan pada saat estimasi atau perhitungan, dan bahkan pada saat melakukan pembangunan perangkat lunak dari mulai komponen. Jadi dibutuhkan sebuah ketelitian dan kesabaran dalam membangun sebuah perangkat lunak".

\section{Rekam Medis}

Menurut Permenkes No.749a 1989, "rekam medis adalah berkas yang berisikan catatan, dan dokumen tentang identitas pasien, pemeriksaan, pengobatan, tindakan dan pelayanan lain kepada pasien pada sarana pelayanan kesehatan".

Fungsi atau tujuan dari rekam medis adalah untuk menunjang tercapainya tertib administrasi dalam rangka upaya peningkatan pelayanan kesehatan. Tanpa didukung suatu sistem pengelolaan rekam medis yang baik dan benar, maka tertib administrasi tidak akan berhasil. 


\section{Kegunaan Rekam Medis}

a. Aspek Administrasi

Suatu berkas rekam medis mempunyai nilai administrasi, karena isinya menyangkut tindakan berdasarkan wewenang dan tanggung jawab sebagai tenaga medis dan perawat dalam mencapai tujuan pelayanan kesehatan.

b. Aspek Medis

Catatan tersebut dipergunakan sebagai dasar untuk merencanakan terapi pengobatan dan perawatan yang harus diberikan kepada pasien

Contoh :

1) Identitas pasien name, age, sex, address, marriage status, etc.

2) Anamnesis "fever" how long, every time, continuously, periodic?

3) Physical diagnosis head, neck, chest,etc.

4) Laboratory examination, another supporting examination, etc.

c. Aspek Hukum

Menyangkut masalah adanya jaminan kepastian hukum atas dasar keadilan, dalam rangka usaha menegakkan hukum serta penyediaan bahan tanda bukti untuk menegakkan keadilan

d. Aspek Keuangan

Isi Rekam Medis dapat dijadikan sebagai bahan untuk menetapkan biaya pembayaran pelayanan. Tanpa adanya bukti catatan tindakan pelayanan, maka pembayaran tidak dapat dipertanggungjawabkan.

e. Aspek Penelitian

Berkas Rekam medis mempunyai nilai penelitian, karena isinya menyangkut data/informasi yang dapat digunakan sebagai aspek penelitian.

f. Aspek Pendidikan

Berkas Rekam Medis mempunyai nilai pendidikan, karena isinya menyangkut data/informasi tentang kronologis dari pelayanan medik yang diberikan pada pasien.

g. Aspek Dokumentasi

Isi Rekam medis menjadi sumber ingatan yang harus didokumentasikan dan dipakai sebagai bahan pertanggungjawaban dan laporan sarana kesehatan.
Berdasarkan aspek-aspek tersebut, maka rekam medis mempunyai kegunaan yang sangat luas yaitu :

1. Sebagai alat komunikasi antara dokter dengan tenaga kesehatan lainnya yang ikut ambil bagian dalam memberikan pelayanan kesehatan.

2. Sebagai dasar untuk merencanakan pengobatan/perawatan yang harus diberikan kepada seorang pasien.

3. Sebagai bukti tertulis atas segala tindakan pelayanan, perkembangan penyakit dan pengobatan selama pasien berkunjung/dirawat di Rumah sakit.

4. Sebagai bahan yang berguna untuk analisa, penelitian dan evaluasi terhadap program pelayanan serta kualitas pelayanan.

5. Melindungi kepentingan hukum bagi pasien, sarana kesehatan maupun tenaga kesehatan yang terlibat.

6. Menyediakan data dan informasi yang diperlukan untuk keperluan pengembangan program, pendidikan dan penelitian.

7. Sebagai dasar di dalam perhitungan biaya pembayaran pelayanan kesehatan.

8. Menjadi sumber ingatan yang harus didokumentasikan serta bahan pertanggungjawaban dan laporan.

\section{Metode Penelitian}

Rekam Medis Digital ini dibuat menggunakan metodelogi prototype. Prototype merupakan metodologi pengembangan software yang menitik-beratkan pada pendekatan aspek desain, fungsi dan user-interface. Developer dan User fokus pada user-interface dan bersama-sama mendefinisikan spesifikasi, fungsi, desain dan bagaimana software bekerja. Developer dan User bertemu dan melakukan komunikasi dan menentukan tujuan umum, kebutuhan yang diketahui dan gambaran bagian-bagian yang akan dibutuhkan. Developer mengumpulkan detail dari kebutuhan dan memberikan suatu gambaran dengan blueprint (prototype).

Menurut Roger S. Pressman (2005:42), "pendekatan prototyping sangat cocok digunakan untuk sistem atau perangkat lunak yang dibangun mengikuti kebutuhan pengguna, metode ini sangat sesuai diterapkan dalam proses perancangan 
perangkat lunak yang akan dibangun. Tahapan-tahapan dalam model proses prototype mewakili tahapan pengembangan desain perangkat lunak baru yang akan dibangun".

Menurut Sommerville (2007:87), "prototype adalah versi awal dari sistem perangkat lunak yang digunakan untuk mendemonstrasikan konsep, mencoba pilihan rancangan, dan secara umum, mencari lebih jauh tentang kesalahan dan solusi yang dimungkinkan".

Proses tersebut akan diketahui detaildetail yang harus dikembangkan atau ditambahkan oleh developer terhadap blueprint, atau menghapus detail-detail yang tidak diperlukan oleh user. Proses akan terjadi terus menerus sehingga produk sesuai dengan keinginan dari user.

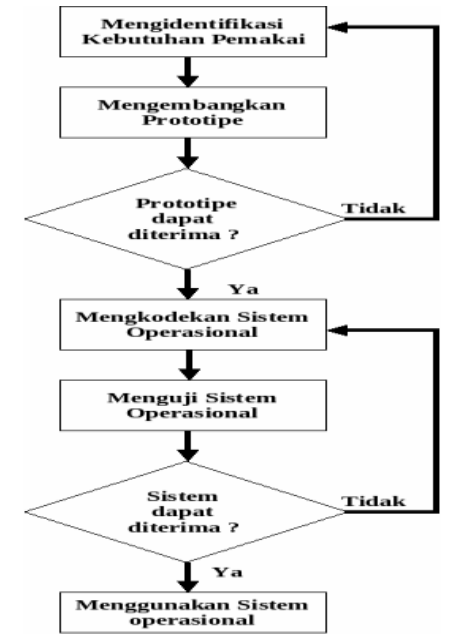

Gambar 1 Tahapan Prototype

Perancangan sebuah perangkat lunak sering terjadi seorang user hanya memberikan gambaran secara umum tentang perangkat lunak yang akan dibuat tanpa menyebutkan secara detil input, proses, dan output apa saja yang dibutuhkan. Dan sebaliknya seorang Developer kurang memperhatikan intelegensi atau kemampuan user yang akan menggunakan perangkat lunak dan interface yang dapat membuat perangkat lunak yang akan digunakan oleh user bersifat user-friendly. Dengan menggunakan metode prototyping antara
Developer dan User dapat saling berinteraksi. Berikut penjelasan tahapan prototype:

1. Mengidentifikasi Kebutuhan Pemakai. Adanya komunikasi antara Developer dengan user mengenai tujuan pembuatan dan analisis kebutuhan untuk sebuah perangkat lunak yang akan dibuat.

2. Mengembangkan Prototype.

Developer membuat satu atau beberapa prototype sebagai bahan pertimbangan bagi user.

3. Menentukan Diterima atau tidaknya Prototype.

Developer mendemonstrasikan prototype yang telah dibuat kepada user, apabila prototype diterima oleh user, maka dilanjutkan kelangkah selanjutnya. Jika tidak, maka kembali lagi ke langkah pertama.

4. Pengkodean Sistem Operasional.

Prototype yang telah diterima oleh user dijadikan bahan dasar dalam membangun sistem operasional.

5. Pengujian Sistem Operasional.

Sistem operasional yang sudah jadi diuji terlebih dahulu sebelum diberikan kepada User.

6. Menetukan Diterima atau Tidaknya Sistem Operasional.

Sistem operasional yang telah diuji, demonstrasikan kepada user untuk menentukan diterima atau tidaknya sistem yang telah dibuat. Jika diterima maka dilanjutkan kelangkah selanjutnya, namun jika tidak maka diulang kembali kelangkah 4.

7. Membuat Sistem Operasional.

Pendekatan ini diikuti ketika prototype ditujukan hanya untuk menampilkan seperti sistem operasional, namun tidak dimaksudkan untuk memuat semua elemen penting.

Membangun sebuah prototype harus ada kesepakatan antara Developer dan user bahwa prototype dibangun untuk mendefinisikan kebutuhan.

\section{Rencana Validasi}

Tujuan dibangunnya aplikasi ini adalah untuk meningkatkan efisiensi dan efektifitas kerja pada Klinik Medika Kecamatan Conggeang baik 
dari segi pendaftaran pasien maupun penyimpanan data pasien. Dengan demikian perlu adanya sebuah validasi model untuk mengetahui kesesuaian hasil dengan tujuan. Validasi dilakukan dengan cara di berikannya kuisioner kepada para user setelah mencoba menggunakan aplikasi rekam medis digital yang telah jadi.

Tabel 2. Rencana Pengujian Fungsi Model

\begin{tabular}{|c|c|c|}
\hline No & Kelas Uji & Butir uji \\
\hline 1 & Halaman Login & $\begin{array}{l}\text { Menampilkan } \\
\text { halaman login }\end{array}$ \\
\hline 2 & $\begin{array}{l}\text { Halaman } \\
\text { Registrasi }\end{array}$ & $\begin{array}{l}\text { Menampilkan } \\
\text { halaman daftar akun }\end{array}$ \\
\hline 3 & $\begin{array}{l}\text { Halaman Data } \\
\text { Pasien }\end{array}$ & $\begin{array}{l}\text { Menampilkan } \\
\text { Halaman data passien }\end{array}$ \\
\hline 4 & $\begin{array}{l}\text { Halaman Edit } \\
\text { Data Pasien }\end{array}$ & \begin{tabular}{|lr} 
Menampilkan & \\
halaman & untuk \\
mengubah & data \\
pasien & \\
\end{tabular} \\
\hline 5 & $\begin{array}{l}\text { Halaman riwayat } \\
\text { penyakit }\end{array}$ & $\begin{array}{l}\text { Menampilkan } \\
\text { halaman riwayat } \\
\text { penyakit pasien }\end{array}$ \\
\hline 6 & $\begin{array}{l}\text { Halaman Daaftar } \\
\text { berobat }\end{array}$ & $\begin{array}{l}\text { Menampilkan } \\
\text { pengambilan nomor } \\
\text { antrian }\end{array}$ \\
\hline 7 & $\begin{array}{l}\text { Halaman Lihat } \\
\text { Antrian }\end{array}$ & $\begin{array}{l}\text { Menampilkan } \\
\text { Antrian yang sedang } \\
\text { berlangsung }\end{array}$ \\
\hline 8 & $\begin{array}{l}\text { Halaman Periksa } \\
\text { Pasien }\end{array}$ & $\begin{array}{l}\text { Menampilkan menu } \\
\text { untuk menambah } \\
\text { data riwayat pasien }\end{array}$ \\
\hline 9 & $\begin{array}{l}\text { Halaman Olah } \\
\text { Antrian }\end{array}$ & $\begin{array}{l}\text { Menampilkan proses } \\
\text { pemanggilan nomor } \\
\text { antrian }\end{array}$ \\
\hline 10 & $\begin{array}{l}\text { Popup Gagal } \\
\text { Login }\end{array}$ & $\begin{array}{l}\text { Menampilkan Popup } \\
\text { salah memasukkan } \\
\text { username } \\
\text { password }\end{array}$ \\
\hline 11 & $\begin{array}{l}\text { Popup Sukses } \\
\text { Daftar Berobat }\end{array}$ & $\begin{array}{l}\text { Menampilkan } \\
\text { konfirmasi } \\
\text { daftar berobat }\end{array}$ \\
\hline 12 & $\begin{array}{l}\text { Popup Antrian } \\
\text { Dibatalkan }\end{array}$ & $\begin{array}{l}\text { Menampilkan } \\
\text { konfirmasi } \\
\text { pembatalan antrian }\end{array}$ \\
\hline
\end{tabular}

\begin{tabular}{|l|l|l|}
\hline 13 & $\begin{array}{l}\text { Popup Hapus } \\
\text { Data }\end{array}$ & $\begin{array}{l}\text { Menampilkan } \\
\text { konfirmasi } \\
\text { penghapusan data }\end{array}$ \\
\hline 14 & Popup Logout & $\begin{array}{l}\text { Menampilkan keluar } \\
\text { konfirmasi } \\
\text { dari aplikasi. }\end{array}$ \\
\hline
\end{tabular}

Tabel 3. Rencana Pengujian Kinerja Sistem

\begin{tabular}{|c|c|c|}
\hline No & Sistem & Yang diharapkan \\
\hline 1 & $\begin{array}{l}\text { Tombol "daftar" pada } \\
\text { menu registrasi }\end{array}$ & $\begin{array}{l}\text { Pendaftaran pasien pada } \\
\text { aplikasi }\end{array}$ \\
\hline 2 & $\begin{array}{l}\text { Tombol "masuk" pada } \\
\text { menu utama }\end{array}$ & Login ke dalam aplikasi \\
\hline 3 & $\begin{array}{l}\text { Tombol "Ubah Data" } \\
\text { pada menu Data } \\
\text { Pasien, Data Dokter } \\
\text { dan Data Admin }\end{array}$ & $\begin{array}{l}\text { Mengubah informasi data } \\
\text { pengguna }\end{array}$ \\
\hline 4 & $\begin{array}{l}\text { Tombol "ambi nomor } \\
\text { antrian" pada menu } \\
\text { daftar berobat }\end{array}$ & Muncul Nomor Antrian. \\
\hline 5 & $\begin{array}{l}\text { Tombol "Riwayat } \\
\text { Penyakit" pada menu } \\
\text { riwayat penyakit } \\
\text { pasien }\end{array}$ & $\begin{array}{l}\text { Tampilkan daftar riwayat } \\
\text { penyakit }\end{array}$ \\
\hline 6 & $\begin{array}{l}\text { Tombol "batalkan } \\
\text { antrian" pada menu } \\
\text { lihat antrian }\end{array}$ & $\begin{array}{l}\text { Membatalkan } \\
\text { antrian pasien }\end{array}$ \\
\hline 7 & $\begin{array}{l}\text { Tombol "tambah } \\
\text { diagnosa" pada periksa } \\
\text { pasien }\end{array}$ & $\begin{array}{l}\text { Menambahkan } \\
\text { riwayat pasien }\end{array}$ \\
\hline 8 & $\begin{array}{l}\text { Popup Keluar Aplikasi } \\
\text { pada Menu utama }\end{array}$ & Keluar dari aplikasi \\
\hline
\end{tabular}

\section{Hasil dan Pembahasan}

\section{Pendefinisian Sistem}

Penelitian ini, dikembangkan sebuah model Rekam Medis digital untuk Klinik Medika Kecamatan Conggeang. Model ini dikembangkan dengan berbasis mobile. Rekam Medis Digital Klinik Medika Kecamatan Conggeang ini bertujuan untuk menjadikan fungsi pelayanan kesehatan di Klinik Medika Kecamatan Conggeang menjadi lebih maksimal, efektif dan efisien. Selain itu 
aplikasi ini juga bertujuan untuk bisa melakukan pendaftaran berobat pasien dimana saja (online), sehingga pasien yang akan berobat bisa menggunakan waktu tunggu antrian di klinik untuk berisitirahat di rumah.

\section{Aspek Struktur}

Aspek Struktur pada sistem ini adalah perancangan struktur yang menggambarkan alur proses penyampaian informasi yang akan dikembangkan. Berikut ini merupakan gambaran struktur dari sistem Rekam Medis Digital Klinik Medika Kecamatan Conggeang.

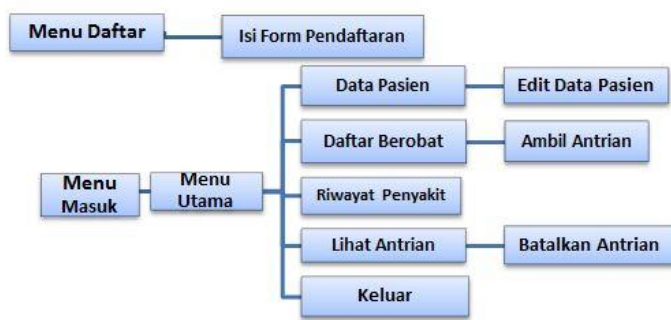

Gambar 2 Aspek Struktur Pasien

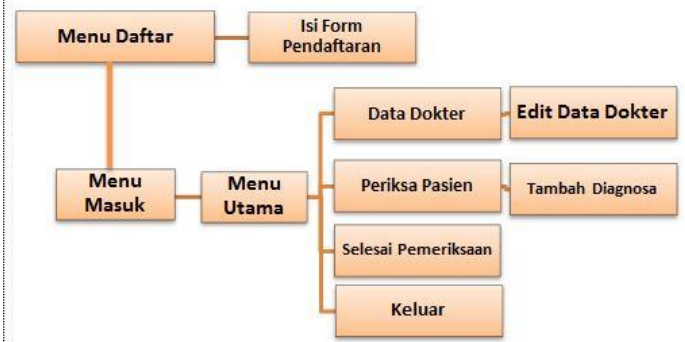

Gambar 3 Aspek Struktur Dokter

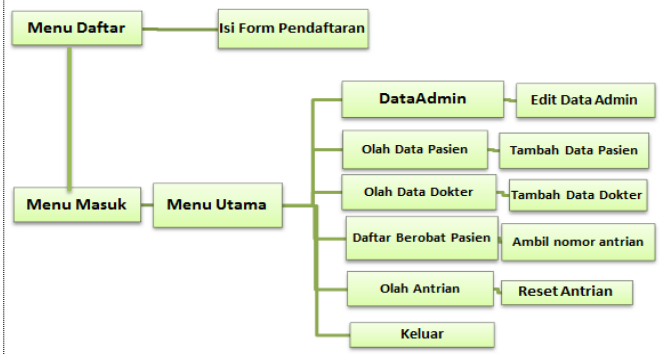

Gambar 4 Aspek Struktur Admin
Berikut adalah perilaku sistem yang merupakan penjelasan dari diagram aspek struktur : Tabel 4. Perilaku Sistem Pasien.

\begin{tabular}{|c|c|}
\hline Nama & Perilaku Sistem \\
\hline Menu Daftar & $\begin{array}{l}\text { Halaman ini merupakan } \\
\text { halaman pendaftaran } \\
\text { bagi pasien baru. }\end{array}$ \\
\hline Form Pendaftaran & $\begin{array}{l}\text { Halaman ini berisi } \\
\text { tentang form pengisian } \\
\text { data pasien. }\end{array}$ \\
\hline Menu Masuk & $\begin{array}{l}\text { Halaman ini merupakan } \\
\text { halaman login pasien } \\
\text { agar bisa mengakses } \\
\text { menu di aplikasi. }\end{array}$ \\
\hline Menu utama & $\begin{array}{l}\text { Halaman ini merupakan } \\
\text { sebuah tampilan awal } \\
\text { ketika aplikasi di } \\
\text { jalankan, didalamnya } \\
\text { terdapat beberapa } \\
\text { tombol yang dihubungka } \\
\text { dengan halaman lainnya. }\end{array}$ \\
\hline Data Pasien & $\begin{array}{l}\text { Menu ini berisi informasi } \\
\text { data Pasien. }\end{array}$ \\
\hline Edit Data Pasien & $\begin{array}{l}\text { Menu ini berisi fasilitas } \\
\text { untuk mengubah } \\
\text { informasi data pasien. }\end{array}$ \\
\hline Daftar Berobat & $\begin{array}{l}\text { Menu ini merupakan } \\
\text { tempat } \\
\text { berobat pasien. }\end{array}$ \\
\hline $\begin{array}{l}\text { Ambil Nomor } \\
\text { Antrian }\end{array}$ & $\begin{array}{l}\text { Menu ini berisi fasilitas } \\
\text { pengambilan antrian } \\
\text { berobat. }\end{array}$ \\
\hline Riwayat Penyakit & $\begin{array}{l}\text { Halaman ini berisi } \\
\text { tentang daftar riwayat } \\
\text { penyakit yang pernah di } \\
\text { derita olehpasien. }\end{array}$ \\
\hline Lihat Antrian & $\begin{array}{lr}\text { Halaman ini } & \text { berisi } \\
\text { fasilitas untukk } & \text { melihat } \\
\text { nomor antrian } & \text { berobat } \\
\text { yang } & \text { sedang } \\
\text { berlangsung.l. } & \end{array}$ \\
\hline Batalkan Antrian & $\begin{array}{l}\text { Halaman ini berisi } \\
\text { fasilitas } \\
\text { ntrian. }\end{array}$ \\
\hline Keluar & Untuk menutup aplikasi. \\
\hline
\end{tabular}

Tabel 5. Perilaku Sistem Admin.

\begin{tabular}{l|l} 
Nama & Perilaku Sistem
\end{tabular}




\begin{tabular}{|c|c|}
\hline Menu Daftar & $\begin{array}{l}\text { Halaman ini merupakan } \\
\text { halaman pendaftaran bagi } \\
\text { admin. }\end{array}$ \\
\hline $\begin{array}{l}\text { Form } \\
\text { Pendaftaran }\end{array}$ & $\begin{array}{l}\text { Halaman ini berisi } \\
\text { tentang form pengisian } \\
\text { data admin. }\end{array}$ \\
\hline Menu Masuk & $\begin{array}{l}\text { Halaman ini merupakan } \\
\text { halaman login admin agar } \\
\text { bisa mengakses menu di } \\
\text { aplikasi. }\end{array}$ \\
\hline Menu utama & $\begin{array}{l}\text { Halaman } \\
\text { sebuah } \\
\text { ketika tampilan awerupakan } \\
\text { jalankan, aplikasi didalamnya } \\
\text { terdapat beberapa tombol } \\
\text { yang dihubungkan } \\
\text { dengan halaman lainnya. }\end{array}$ \\
\hline Data Admin & $\begin{array}{l}\text { Menu ini berisi informasi } \\
\text { data Admin. }\end{array}$ \\
\hline Edit Data Admin & $\begin{array}{l}\text { Menu ini berisi fasilitas } \\
\text { untuk mengubah } \\
\text { informasi data Admin. }\end{array}$ \\
\hline Olah Data Pasien & $\begin{array}{l}\text { Menu ini merupakan } \\
\text { tempat untuk mengolah } \\
\text { data pasien. }\end{array}$ \\
\hline $\begin{array}{l}\text { Tambah Data } \\
\text { Pasien }\end{array}$ & $\begin{array}{l}\text { Menu ini berisi fasilitas } \\
\text { untuk menambahkan } \\
\text { data pasien. }\end{array}$ \\
\hline Olah Data Dokter & $\begin{array}{l}\text { Menu ini merupakan } \\
\text { tempat untuk mengolah } \\
\text { data dokter. }\end{array}$ \\
\hline $\begin{array}{l}\text { Tambah Data } \\
\text { Dokter }\end{array}$ & $\begin{array}{l}\text { Menu ini berisi fasilitas } \\
\text { untuk menambahkan data } \\
\text { dokter. }\end{array}$ \\
\hline $\begin{array}{l}\text { Daftar Berobat } \\
\text { Pasien }\end{array}$ & $\begin{array}{l}\begin{array}{l}\text { Halaman } \\
\text { fasilitas } \\
\text { fasien. }\end{array} \\
\text { pendaftaran } \\
\end{array}$ \\
\hline Ambil Antrian & $\begin{array}{l}\text { Menu ini berisi fasilitas } \\
\text { pengambilan antrian } \\
\text { berobat. }\end{array}$ \\
\hline Olah Antrian & $\begin{array}{l}\text { Halaman ini berisi } \\
\text { fasilitas untuk mengolah } \\
\text { data antrian pasien. }\end{array}$ \\
\hline
\end{tabular}

\begin{tabular}{|l|lr|}
\hline Reset Antrian & $\begin{array}{l}\text { Halaman ini } \\
\text { fasilitas berisi } \\
\text { menghapus } \\
\text { pasien. }\end{array}$ \\
\hline Keluar & Untuk menutup aplikasi. \\
\hline
\end{tabular}

Tabel 6. Perilaku Sistem Dokter.

\begin{tabular}{|c|c|}
\hline Nama & Perilaku Sistem \\
\hline Menu Daftar & $\begin{array}{l}\text { Halaman } \\
\text { halaman } \\
\text { dokter. }\end{array}$ \\
\hline Form Pendaftaran & $\begin{array}{l}\text { Halaman ini berisi tentang } \\
\text { form pengisian data dokter. }\end{array}$ \\
\hline Menu Masuk & $\begin{array}{l}\text { Halaman ini merupakan } \\
\text { halaman login dokter agar bisa } \\
\text { mengakses menu di aplikasi. }\end{array}$ \\
\hline Menu utama & $\begin{array}{l}\text { Halaman ini } r \text { merupakan } \\
\text { sebuah tampilan } \\
\text { aplikasi kal ketika } \\
\text { didalamnya terdapat beberapa } \\
\text { tombol yang dihubungka } \\
\text { dengan halaman lainnya. }\end{array}$ \\
\hline Data Dokter & $\begin{array}{l}\text { Menu ini berisi informasi data } \\
\text { dokter. }\end{array}$ \\
\hline Edit Data Dokter & $\begin{array}{l}\text { Menu ini berisi fasilitas untuk } \\
\text { mengubah informasi data } \\
\text { dokter. }\end{array}$ \\
\hline Periksa Pasien & $\begin{array}{l}\text { Menu ini merupakan tempat } \\
\text { untuk memanggil pasien yang } \\
\text { akan di periksa. }\end{array}$ \\
\hline Diag & $\begin{array}{l}\text { Menu ini merupakan tempat } \\
\text { untuk memasukkan hasil } \\
\text { diagnosa dokter terhadap } \\
\text { pasien. }\end{array}$ \\
\hline $\begin{array}{l}\text { Selesai } \\
\text { Pemeriksaan }\end{array}$ & $\begin{array}{l}\text { Menu ini berfungsi untuk } \\
\text { menyelesaikan } \\
\text { pemeriksaan. }\end{array}$ \\
\hline Keluar & Untuk menutup aplikasi. \\
\hline
\end{tabular}




\section{Formulasi Class Diagram}

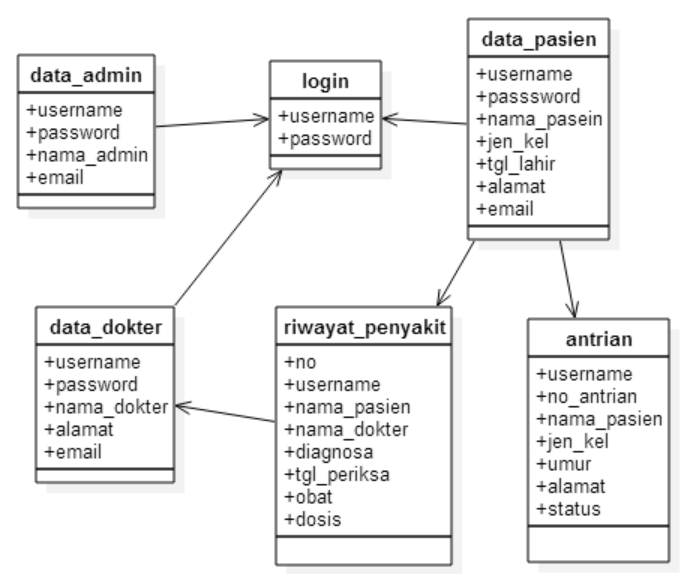

Gambar 5 Class Diagram Rekam medis digital.

\section{Hasil Tampilan Aplikasi Rekam Medis}

Bagian ini akan disajikan beberapa tampilan yang digunakan untuk mengelola rekam medis digital. Adapun tampilannya adalah sebagai berikut :

1. Tampilan Halaman Login
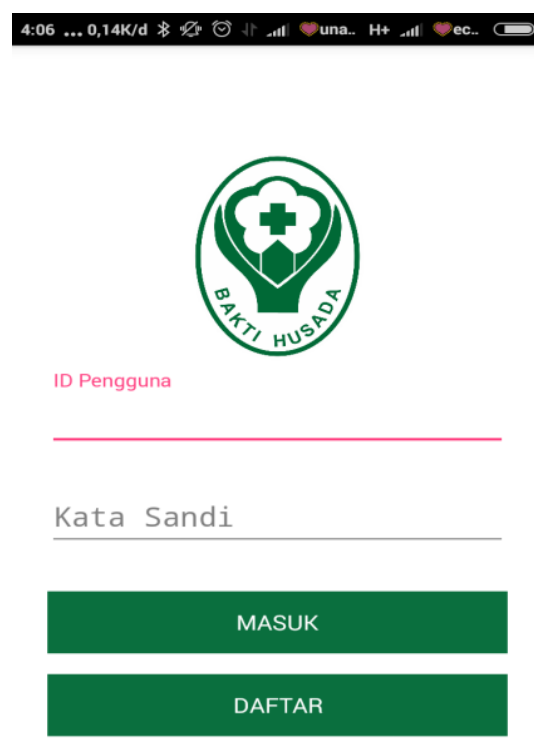

Gambar 6 Halaman Menu utama
2. Halaman Menu Utama Pasien

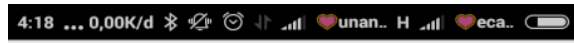

\section{DATA PASIEN}

DAFTAR BEROBAT

RIWAYAT PENYAKIT

LIHAT ANTRIAN

KELUAR

Gambar 7 Halaman Menu Utama Pasien

3. Halaman Daftar Berobat

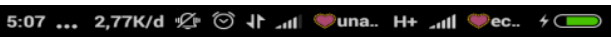

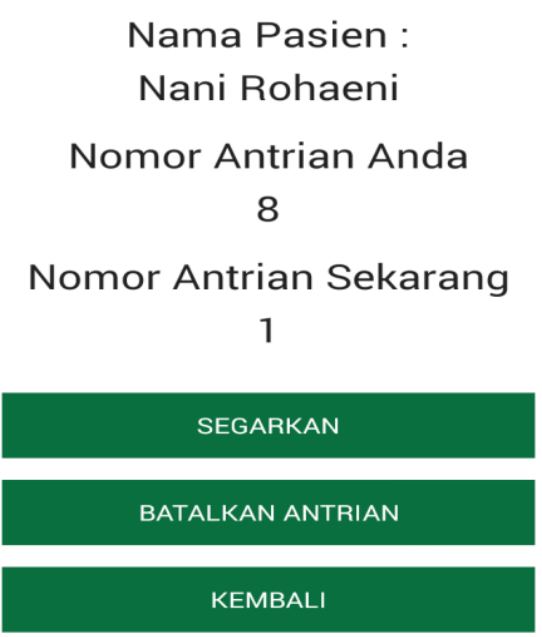

Gambar 8 Daftar Berobat 
4. Halaman Riwayat Pasien

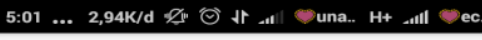

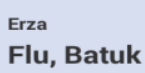

Gambar 9 Halaman Riwayat Penyakit

5. Halaman Tambah Diagnosa $4: 44 \ldots 0,00 \mathrm{~K} / \mathrm{d}$ "..

ID Pasien
eca
ID Pasien
eca

Hasil Diagnosa

Flu, Batuk

Obat

paracetamol

Dosis

$3 \times 1 \mid$

\section{TAMBAH RIWAYAT}

Gambar 10 Halaman Tambah Diagnosa

\section{Validasi Model}

Pengujian validasi model merupakan tahap akhir dari perancangan sistem yang dibuat, program dianggap berhasil jika semua proses berjalan dengan baik serta sesuai dengan tujuan yang ingin dicapai. Dalam pengujian program dilakukan dengan menggunakan metode Black Box Test untuk mengetahui keselahan sistem yang diuji.

Tabel 7. Rencana Pengujian Fungsi Model

\begin{tabular}{|l|l|c|}
\hline No & \multicolumn{1}{|c|}{ Kelas Uji } & Hasil \\
\hline 1 & Halaman Login & V \\
\hline 2 & Halaman Registrasi & V \\
\hline 3 & Halaman Data Pasien & V \\
\hline 4 & Halaman Edit Data Pasien & V \\
\hline 5 & Halaman riwayat penyakit & V \\
\hline 6 & Halaman Daaftar berobat & V \\
\hline 7 & Halaman Lihat Antrian & V \\
\hline 8 & Halaman Periksa Pasien & V \\
\hline 9 & Halaman Olah Antrian & V \\
\hline 10 & Popup Gagal Login & V \\
\hline 11 & $\begin{array}{l}\text { Popup Sukses Daftar } \\
\text { Berobat }\end{array}$ & V \\
\hline 12 & Popup Antrian Dibatalkan & V \\
\hline 13 & Popup Hapus Data & V \\
\hline 14 & Popup Logout & V \\
\hline
\end{tabular}

Tabel 8: Rencana Pengujian Kinerja Sistem

\begin{tabular}{|l|l|c|}
\hline No & \multicolumn{1}{|c|}{ Sistem } & Hasil \\
\hline 1 & $\begin{array}{l}\text { Tombol "daftar" } \\
\text { pada menu } \\
\text { registrasi }\end{array}$ & Sesuai \\
\hline 2 & $\begin{array}{l}\text { Tombol "masuk" } \\
\text { pada menu utama }\end{array}$ & Sesuai \\
\hline 3 & $\begin{array}{l}\text { Tombol "Ubah } \\
\text { Data" pada menu } \\
\text { Data Pasien, Data } \\
\text { Dokter dan Data } \\
\text { Admin }\end{array}$ & Sesuai \\
\hline 4 & $\begin{array}{l}\text { Tombol "ambi } \\
\text { nomor antrian" } \\
\text { pada menu daftar } \\
\text { berobat }\end{array}$ & Sesuai \\
\hline 5 & $\begin{array}{l}\text { Tombol "Riwayat } \\
\text { Penyakit" pada }\end{array}$ & Sesuai \\
\hline
\end{tabular}




\begin{tabular}{|l|l|c|}
\hline & $\begin{array}{l}\text { menu riwayat } \\
\text { penyakit pasien }\end{array}$ & \\
\hline 6 & $\begin{array}{l}\text { Tombol "batalkan } \\
\text { antrian" pada menu } \\
\text { lihat antrian }\end{array}$ & Sesuai \\
\hline 7 & $\begin{array}{l}\text { Tombol "tambah } \\
\text { diagnosa" pada } \\
\text { periksa pasien }\end{array}$ & Sesuai \\
\hline 8 & $\begin{array}{l}\text { Popup Keluar } \\
\text { Aplikasi pada } \\
\text { Menu utama }\end{array}$ & Sesuai \\
\hline
\end{tabular}

\section{Kesimpulan dan Saran}

\section{Kesimpulan}

Adanya aplikasi rekam medis digital ini mengurangi terjadinya antrian pasien. Selain itu, aplikasi ini memungkinkan pasien ataupun paramedis untuk mengetahui riwayat penyakit yang pernah dialami oleh pasien sehingga sangat membantu dalam proses penanganan medis. Pada aplikasi rekam medis ini dapat digunakan sebagai media penyimpanan dokumen pasien yang efektif dan efisien karena dapat mengurangi terjadinya kehilangan dan kerusakan data.

\section{Saran}

Saran untuk pengembangan aplikasi rekam medis digital ini adalah sebagai berikut:

Aplikasi Rekam medis digital pada Klinik Medika Kecamatan Conggeang ini belum adanya backup dan restore database juga belum adanya laporan dalam bentuk pdf. Oleh karena itu sistem harus dikembangkan lagi agar menjadi lebih sempurna.

\section{Daftar Pustaka}

J. C. Ellis, Heidi., Nevada, J. Fernando (2009). Software Engineering: Effective Teaching and Learning Approaches, Hershey: IGI Global.

Pressman, Roger S (2005). Software Engineering: A Practitioner's Approach, New York: McGraw Hill.

DiMarzio, J.F (2008). Android ${ }^{T M}$ : A Programmer's Guide, New York: Mc Graw Hill.

Murya, Yosef (2014). Pemrograman Android BlackBox, Jakarta: Jasakom.

Kadir, Abdul (2004). Dasar Pemrograman Java 2, Yogyakarta: Andi.

Sommerville, Ian (2007). Software Engineering (8th ed.), Harlow: Pearson Education.

Fowler, Martin (2005). UML Distilled Edisi 3, Yogyakarta: Andi.

Munawar (2005). Pemodelan Visual menggunakan $U M L$, Yogyakarta: Graha Ilmu. 